\title{
Schistosoma mansoni and Schistosoma heamatobium Infection and Nutritional Status of Children in the Hydro-Agricultural Complex Zone of Sourou, Burkina Faso
}

\author{
Léon G. B. Savadogo1*, Boubacar Savadogo², Dayéri Dianou², Jean Noël Poda² \\ ${ }^{1}$ Department of Epidemiology and Public Health-Child and Mother Health, Nutrition and Survival Unit, Institut \\ Supérieur des Sciences de la Santé, Université Polytechnique de Bobo Dioulasso, Bobo Dioulasso, Burkina Faso \\ ${ }^{2}$ Institut de Recherche en Sciences de la Santé, Ouagadougou, Burkina Faso \\ Email: "gueswende@hotmail.com
}

Received 5 February 2014; revised 17 March 2014; accepted 3 April 2014

Copyright (C) 2014 by authors and Scientific Research Publishing Inc. This work is licensed under the Creative Commons Attribution International License (CC BY). http://creativecommons.org/licenses/by/4.0/ (c) (i) Open Access

\section{Abstract}

In developing countries, efforts to face food insecurity were revealed by construction of dams and hydro-agricultural managements. This study aimed to establish sanitary consequences in a hydroagricultural zone. Methods: Data from 1847 children were analysed. Kato-Katz and concentration in MIF were used for intestinal parasites; research of microscopic haematury was used for urinary schistosomiasis. Nutritional status was estimated by WHZ and HAZ indexes. Association between malnutrition and independents variables was measured in univariate and multivariate analysis. Results: Among children, $80.1 \%$ were infested by at least one parasite, $30.8 \%$ by $S$. mansoni and 49.6\% by $S$. haematobium. Prevalence of emaciation and prevalence of stunting were respectively, $32.6 \%$ and $25.5 \%$. In the multivariate analysis: Age: $(1-3$ y age group, $O R=2.92,4-6$ y age group $\mathrm{OR}=1.85, p<0.001) ; S$. mansoni $(\mathrm{OR}=1.27, p<0.027)$ and $S$. haematobium (high $\mathrm{OR}=1.53$, low $\mathrm{OR}=1.44, p=0.008)$, were associated with emaciation. Age: $(4-6 \mathrm{y}$ age group, $\mathrm{OR}=1.78,7-11 \mathrm{y}$ age group $\mathrm{OR}=2.55, p<0.001$ ) and $S$. haematobium (high $\mathrm{OR}=1.58$, low $\mathrm{OR}=1.28, p=0.005$ ), were associated with emaciation. Conclusion: Development of bilharziasis (urinary and intestinal) with increased morbidity and malnutrition, attenuate benefits expected from hydro-agricultural managements. It is important to invest in the control of water-related diseases, which are amplified by hydro-agricultural managements.

"Corresponding author.

How to cite this paper: Savadogo, L.G.B., Savadogo, B., Dianou, D. and Poda, J.N. (2014) Schistosoma mansoni and Schistosoma heamatobium Infection and Nutritional Status of Children in the Hydro-Agricultural Complex Zone of Sourou, Burkina Faso. Occupational Diseases and Environmental Medicine, 2, 13-18. http://dx.doi.org/10.4236/odem.2014.22002 


\section{Keywords}

\section{Schistosoma, Nutritional Status, Children, Hydro-Agricultural Complex}

\section{Introduction}

One of the indispensable conditions to solve the African food deficits is to concentrate efforts on the use and control of water abilities. In Burkina Faso, these efforts were revealed by the construction of dams and hydroagricultural managements. Some consider these amenities as a "weapon against hunger", and others worry about the negative impacts on environment and health of populations especially, on the amplification of water-related diseases. Chronic infectious diseases, poverty, and malnutrition compromise the growth and development of children [1]. It is estimated that a third of the cases of low growth can be assigned to diarrhoea and equal infections, even in the case of a sub-clinical infection [2]. Among the parasite infections, other than malaria, infections by Schistosoma mansoni and Schistosoma heamatobium are frequent and serious in the developing countries [3]. Schistosoma heamatobium is responsible of urinary complications, bladder cancer, and anaemia while Schistosoma mansoni is assigned to hepatosplenomegaly and portal hypertension. The infection can be severe with a high lethality. Some authors reported that Schistosoma mansoni is associated with a deficient nutritional statute among adults [4], and children [5] [6]. This study on Schistosoma mansoni and Schistosoma heamatobium infections and nutritional status in the hydro-agricultural zone of Sourou aims to establish a balance of the main sanitary consequences.

\section{Material and Methods}

\subsection{Study Design and Site}

We carried out cross-sectional study from the zone of Sourou, characterized by a north-Soudanian climate with a rainfall inferior to $900 \mathrm{~mm}$. The water resources comprise the Mouhoun, the reserve of Sourou, the ponds and temporary rivers in the villages. Sourou was an affluent distributary of the Mouhoun River until the construction of the Lery Dam in 1976. In 1985, the installation of a foundation raft on the Mouhoun River and the opening of a canal led to the transit of water of Mouhoun coming from the western south towards the Sourou. Thus, this installation allows the mobilization of a great quantity of water throughout the Sourou region for the irrigation of cultures. Therefore, between the traditional villages of Lanfiera and Di large cooperatives were progressively established nixing the irrigated perimeters at Guiedougou, Niassan, and Debe in 1967, 1986, and 1996, respectively, with the installation of producers coming from different regions of the country.

\subsection{Study Population}

Parasitological surveys were carried out by a multidisciplinary team including epidemiologists, biologists, and medical assistants for the epidemiological control of water-related diseases in the hydro-agricultural complex of Sourou. For the investigations in the different villages, the administrative, sanitary, and village authorities were informed and their support requested. Children upper $\geq 1$ year old were systematically included in the sample for examination. For this analysis, data from 1847 children were used.

\subsection{Parasitological Analysis}

For urinary schistosomiasis, research of microscopic haematury with the reactive strips Hémastix ${ }^{\circledR}$ of Bayer has been used. This method, which is adapted to large-scale investigations, is convenient, and allows defining high and medium levels of haematury. A positive result indicates an infestation by Schistosoma haematobium. The method was validated in comparison with the urines filtration method [7]. For stools examination, sterilized plastic pots were distributed. From the sample obtained, a fraction of about $2-3$ grams was taken and added to $10 \mathrm{ml}$ of physiologic serum, then filtrated through 2 paper-filter layers, and centrifuged. The precipitate was dissolved in a mixture consisting of $10 \mathrm{ml}$ Methiolate-Iodure-Formol (MIF), $3 \mathrm{ml}$ ether, then, centrifuged. The technique of Kato-Katz and the method of concentration in MIF were used to analyse the stools for the presence of intestinal parasites including Schistosoma mansoni. 
The stools and urines examinations were performed at the field as described above, using a mobile laboratory.

Children positive for haematury and/or Schistosoma mansoni have received an adapted treatment with Biltricide.

\subsection{Nutritional Status Evaluation}

The nutritional status evaluation was performed base on anthropometrical indicators. Children height and weight were measured with a height gauge and scales adapted to the child age, respectively. The measurements were performed by medical doctors and medical assistants. Weight-for-Height Z-score (WHZ) and Height-for-Age Z-score (HAZ) indexes, for respectively acute malnutrition (emaciation) and stunting, were calculated using the Epinut software program. The index were expressed in Z-score and compared to the NCHS/CDC/WHO reference [8]. Each index was categorized in two groups: children with an index $<-2$ SD under the median of the reference population were considered in malnutrition (emaciation or stunting).

\subsection{Statistical Analysis}

Usual statistics methods were applied. We used Pearson's Chi square test or Fisher's exact test to compare proportions. Malnutrition (emaciation and stunting) Odds ratio with their confidence interval (CI 95\%) were estimated. Adjusted Odds ratio and their CI 95\% were derived from the final model without interactions, from the logistical regression method. The $p$ values used for the final model variables were those corresponding to the Chi 2 of Wald. The following lower and upper standard deviation (SD) boundaries have been used: WHZ ( -4 , $+6)$, HAZ $(-6,+6)$ and WAZ $(-6,+6)$. The data were analyzed using SPSS software.

\section{Results}

Of the 1847 children, the proportion of male was 54.4\%, the median age was 6 years with minimum and maximum age respectively, 1 and 10 years. Among these children, $80.1 \%$ were infested by at least one parasite (helminthe or other parasite), $30.8 \%$ by S. mansoni and $49.6 \%$ by $S$. haematobium. The prevalence of acute malnutrition (emaciation) and stunting (chronic malnutrition) were respectively, 32.6\% and 25.5\% (Table 1).

Table 1. Repartition of children according to demographic characteristics, type of parasite, nutritional status in Z-score weight/height and Z-score height/age.

\begin{tabular}{ccc}
\hline & $\mathrm{n}$ & Percentage \\
Sex & 1005 & 54.4 \\
Boys & 842 & 45.6 \\
Girls & & \\
Age (year) & 555 & 30.0 \\
$1-3$ & 902 & 48.8 \\
$4-6$ & 390 & 21.1 \\
$7-11$ & & \\
At least one parasite ${ }^{\mathrm{a}}$ & 1480 & 80.1 \\
Present & 367 & 19.9 \\
Absent & & \\
Schistosoma haematobium & 333 & 18.0 \\
High & 584 & 31.6 \\
Low & 930 & 50.4 \\
Absent & & \\
Schistosoma mansoni & 568 & 30.8 \\
Present & 1279 & 69.2 \\
Absent & & \\
WHZ & 602 & 32.6 \\
$\leq-2$ DS & 1245 & 67.4 \\
>-2 DS & & 25.5 \\
HAZ & 471 & 74.5 \\
>-2 DS & 1376 & \\
>-2 DS & & \\
\hline
\end{tabular}

a“"at least one parasite” includes helminthes, S. mansoni and S. haematobium. 
In the univariate analysis: Age: ( 1 - 3 y age group, $\mathrm{OR}=2.6,4-6$ y age group $\mathrm{OR}=1.75, p<0.001)$; at least one parasite (OR $=1.60, p<0.001)$; $S$. mansoni $(\mathrm{OR}=1.42, p=0.001)$ and $S$. haematobium (high level $\mathrm{OR}=$ 1.58 , low level $\mathrm{OR}=1.37, p=0.001$ ) were associated with emaciation. Age $(4-6$ y age group $\mathrm{OR}=1.66,7-10$ $\mathrm{y}$ age group $\mathrm{OR}=2.3, \mathrm{p}<0.001)$; at least one parasite $(\mathrm{OR}=1.48, p=0.006)$, $S$. mansoni $(\mathrm{OR}=1.39, p=$ 0.004 ) and $S$. haematobium (high level $\mathrm{OR}=1.61$, low level $\mathrm{OR}=1.43, p=0.001$ ) were associated with stunting (Table 2, Table 3).

In the multivariate analysis: Age: $(1-3$ y age group, $\mathrm{OR}=2.92,4-6$ y age group $\mathrm{OR}=1.85, p<0.001)$; $S$. mansoni ( $\mathrm{OR}=1.27, p<0.027$ ) and $S$. haematobium (high level $\mathrm{OR}=1.53$, low level $\mathrm{OR}=1.44, p=0.008$ ), are associated with emaciation. Age: $(4-6$ y age group, $\mathrm{OR}=1.78,7-11$ y age group $\mathrm{OR}=2.55, p<0.001$ ) and S. haematobium (high level OR $=1.58$, low level $\mathrm{OR}=1.28, p=0.005$ ), are associated with stunting (Table 2, Table 3).

\section{Discussion}

Some authors reported a significant influence of hydro-agricultural managements on bilharziasis evolution [9]-[16]. These managements favour the installation of molluscs, intermediate hosts of schistosomiasis, and the increase of the human-parasite contact [9] [14] [15]. In the hydro-agricultural complex of Sourou, the prevalence of uro-genital bilharziasis has been increasing from $19 \%$ in 1954 to more than $70 \%$ in 1998 [14]. The digestive bilharziasis, almost absent until 1987, reached a prevalence rate of 69\% in some villages of Sourou [9] [11]-[16]. This study confirms the results obtained in other studies regarding the high parasite prevalence observed for young child, especially for S. mansoni [11]-[16].

We observed that $80 \%$ of children were infested by at least one parasite (helminthe or other type of parasite). The use of latrines to eliminate excreta remains very limited, do to: on the one hand the absence of installation, and on the other hand to none adapted socio-cultural practices. For waste treatment, in general there is no efficient system. In rural area, living conditions are precarious and the cohabitation between domestic animals and human create promiscuity situations. All these situations lead to the development of faecal peril-related pathologies. Nutritional status is a result of several factors: eating behaviours, food disposability, environment healthiness, infectious and parasitic diseases, education and socio-economic standards. Thus, nutritional standard can be considered as a "global indicator of development" [10]. From the results we obtained on children nutritional status (32.5\% of emaciation, and $25.5 \%$ of stunting), it appears clearly that the impact of the Sourou hydro-ag-

Table 2. Risk factors for emaciation (unadjusted and adjusted OR).

\begin{tabular}{|c|c|c|c|c|c|c|}
\hline \multirow[b]{2}{*}{ Variables } & \multirow[b]{2}{*}{$\mathbf{n}$} & \multirow[b]{2}{*}{ \% Emaciation } & \multicolumn{2}{|c|}{ Univariate } & \multicolumn{2}{|c|}{ Multivarite } \\
\hline & & & $\begin{array}{l}\text { Unadjusted } \\
\text { OR [IC 95\%] }\end{array}$ & $p$ & $\begin{array}{c}\text { Adjusted } \\
\text { OR [IC 95\%]* }\end{array}$ & $p^{* *}$ \\
\hline \multicolumn{7}{|l|}{ Age (year) } \\
\hline $1-3$ & 555 & 41.3 & $2.6[1.93-3.49]$ & & $2.92[2.16-3.95]$ & \\
\hline $4-6$ & 902 & 32.2 & $1.75[1.32-2.32]$ & $<0.001$ & $1.85[1.39-2.46]$ & $<0.001$ \\
\hline $7-11$ & 390 & 21.3 & 1.00 & & 1.00 & \\
\hline \multicolumn{7}{|l|}{ Sex } \\
\hline Girls & 842 & 32.1 & $0.96[0.79-1.16]$ & 0.65 & & \\
\hline Boys & 1005 & 33.0 & 1.00 & & & \\
\hline \multicolumn{7}{|c|}{ At least one parasite } \\
\hline Present & 1480 & 34.5 & $1.60[1.23-2.07]$ & $<0.001$ & & \\
\hline Absent & 367 & 24.8 & 1.00 & & & \\
\hline \multicolumn{7}{|c|}{ Schistosoma mansoni } \\
\hline Present & 568 & 38.0 & $1.42[1.15-1.75]$ & 0.001 & $1.27[1.02-1.58]$ & 0.027 \\
\hline Absent & 1279 & 30.2 & 1.00 & & 1.00 & \\
\hline \multicolumn{7}{|c|}{ Schistosoma haematobium } \\
\hline High & 333 & 38.7 & $1.58[1.21-2.05]$ & & $1.53[1.16-2.01]$ & \\
\hline Low & 584 & 35.4 & $1.37[1.10-1.71]$ & 0.001 & $1.44[0.96-1.53]$ & 0.008 \\
\hline Absent & 930 & 28.6 & 1.00 & & 1.00 & \\
\hline
\end{tabular}

\footnotetext{
*Adjusted OR of the logistic regression final model for the association between the socio-demographic variables, parasite infections $(\mathrm{n}=1847)$, and emaciation $(\mathrm{n}=602) .{ }^{* *}$ Chi 2 of Wald constant $=-1.93$.
} 
Table 3. Risk factors for stunting (unadjusted and adjusted OR).

\begin{tabular}{|c|c|c|c|c|c|c|}
\hline \multirow{2}{*}{ Variables } & \multirow[b]{2}{*}{$\mathbf{n}$} & \multirow[b]{2}{*}{ \% Stunting } & \multicolumn{2}{|c|}{ Univariate } & \multicolumn{2}{|l|}{ Multivarite } \\
\hline & & & $\begin{array}{l}\text { Unadjusted } \\
\text { OR [IC 95\%] }\end{array}$ & $p$ & $\begin{array}{c}\text { Adjusted } \\
\text { OR [IC 95\%]“ }\end{array}$ & $p^{* *}$ \\
\hline \multicolumn{7}{|l|}{ Age (year) } \\
\hline $1-3$ & 555 & 16.9 & 1.00 & & 1.00 & \\
\hline $4-6$ & 902 & 25.3 & $1.66[1.22-2.25]$ & $<0.001$ & $1.78[1.31-2.43]$ & $<0.001$ \\
\hline $7-11$ & 390 & 31.9 & $2.30[1.67-3.16]$ & & $2.55[1.84-3.53]$ & \\
\hline \multicolumn{7}{|l|}{ Sex } \\
\hline Girls & 842 & 25.1 & $0.96[0.78-1.18]$ & 0.69 & & \\
\hline Boys & 1005 & 25.9 & 1.00 & & & \\
\hline \multicolumn{7}{|c|}{ At least one parasite } \\
\hline Present & 1480 & 26.9 & $1.48[1.12-1.96]$ & 0.006 & & \\
\hline Absent & 367 & 19.9 & 1.00 & & & \\
\hline \multicolumn{7}{|c|}{ Schistosoma mansoni } \\
\hline Present & 568 & 29.9 & 1.39 [1.11 - 1.73] & 0.004 & & \\
\hline Absent & 1279 & 23.5 & 1.00 & & & \\
\hline \multicolumn{7}{|c|}{ Schistosoma haematobium } \\
\hline High & 333 & 30.9 & $1.61[1.22-2.14]$ & & $1.58[1.18-2.11]$ & \\
\hline Low & 584 & 28.4 & $1.43[1.13-1.82]$ & 0.001 & $1.28[1.00-1.64]$ & 0.005 \\
\hline Absent & 930 & 21.7 & 1.00 & & 1.00 & \\
\hline
\end{tabular}

*Adjusted OR of the logistic regression final model for the association between the socio-demographic variables, parasite infections ( $\mathrm{n}=1847)$, and stunting $(\mathrm{n}=602) .{ }^{* *} \mathrm{Chi} 2$ of Wald constant $=-1.93$.

ricultural complex on the development of the principal actors (farmers and their families) looks not good. This situation shows well the unsuitability between the results expected (increase of production) and the effect of the transformed environment. According to the type of management, some authors reported three different situations: a nutritional status improvement in Sri Lanka and Gambia [17] [18], an intermediary situation in Senegal [19], and finally an aggravation of the nutritional status [20].

In Burkina Faso, the medical authorities were constantly alerted by a high under five mortality rate. This mortality could be related to the high malnutrition proportion, which is increased by the considerable importance of S. mansoni and S. haematobium infections in hydro-agricultural complex as confirmed by our study. Malnutrition, parasite infections (helminthe or other parasite), and schistosomiasis have harmful consequences on children intellectual development. At economic level, studies proved that stunting occurred during infancy leads at adult age to a reduction of the productive capacity. Parasite infections and bilharziasis are also responsible of the reduction of production due to the induced morbidity. At medical level, in addition to the reduction of living quality caused by parasite morbidity, malnutrition is responsible of more than $60 \%$ infanto-juvenile mortality, and $S$. mansoni is responsible, through complications, of a high risk of death among children.

\section{Conclusion}

The development of bilharziasis (urinary and intestinal) with increased morbidity and mortality risk, and also malnutrition risk, attenuate the benefits expected from hydro-agricultural managements. Therefore, all actors are challenged to implement these important projects by constant epidemiological surveys and especially the realization of measures for environmental and food hygiene, more particularly the disposability of drinking water. It is important to invest in the control of water-related diseases, which are amplified by hydro-agricultural managements.

\section{References}

[1] The World Bank (1993) World Development Reports 1993: Investing in Health. Oxford University Press, New York.

[2] Allen, L.H. (1994) Nutritional Influences on Linear Growth: A General Review. European Journal of Clinical Nutrition, 48, S75-S89.

[3] WHO (1986) Major Parasitic Infections: A Global Review. World Health Statistics, 39, 145-160.

[4] Mikhail, M.M. and Mansour, M.M. (1982) Complications of Human Schistosomiasis and Their Effect on Levels of 
Plasma Cooper, Zinc and Serum Vitamin A. Human Nutrition. Clinical Nutrition, 36C, 289-296.

[5] De Lima Costa, M.F., Leite, M.L., Rocha, R.S., De Almeida Magalhaës, M.H. and Katz, N. (1988) Anthropometric Measures in Relation to Schistosomiasis Mansoni and Socioeconomic Variables. International Journal of Epidemiology, 17, 880-886. http://dx.doi.org/10.1093/ije/17.4.880

[6] Corbett, E.L., Butterworth, A.E., Fulford, A.J.C., Ouma, J.H. and Sturrock, R.F. (1992) Nutritional Status of Children with Schistosomiasis Mansoni in Two Different Areas of Machakos District, Kenya. Transactions of the Royal Society of Tropical Medicine and Hygiene, 86, 266-273. http://dx.doi.org/10.1016/0035-9203(92)90305-V

[7] Plouvier, S., Leroy, J.C. and Colette, J. (1994) Présentation de deux techniques simples utilisables en enquête épidémiologique de bilharziose urinaire: La filtration des urines et les bandelettes réactives. Xvè Conférence Technique OCCGE.

[8] WHO Working Group (1986) Use and Interpretation of Anthropometric Indicators of Nutritional Status. Bulletin of the WHO, 64, 929-941.

[9] Poda, J.N., Sondo, B. and Parent, G. (2003) Influence des hydro-aménagements sur la distribution des bilharzioses et de leurs hôtes intermédiaires au Burkina Faso. Cahiers Santé, 13, 49-53.

[10] Parent, G., Ouédraogo, A., Zagré, N.M., Compaoré, I., Kambiré, R. and Poda, J.N. (1997) Grands barrages, santé et nutrition en Afrique: Au-délà de la polémique. Cahiers Santé, 7, 417-422.

[11] Poda, J.N., Sorgho, H., Dianou, D., Sawadogo, B., Kambou, T., Parent, G. and Sondo, B. (2001) Profil parasitologique de la Schistosomose urinaire du complexe hydroagricole du Sourou au Burkina Faso. Bulletin de la Société de Pathologie Exotique, 94, 21-24.

[12] Poda, J.N., Dianou, D., Kambou, T., Sawadogo, B. and Sondo, B. (2001) Etude comparative de trois foyers bilharziens à Schistosoma haematobium au Burkina Faso. Bulletin de la Société de Pathologie Exotique, 94, 25-28.

[13] Dianou, D., Poda, J.N., Sorgho, H., Wango, S.P. and Sondo, K.B. (3003) Hydraulic Planning and Schistosomiasis: Case of Sourou in Burkina Faso. Journal of Applied Research in Veterinary Medicine, 1, 105-111.

[14] Poda, J.N., Traoré, A. and Sondo, K.B. (2004) L’endémie bilharzinne au Burkina F. Bulletin de la Société de Pathologie Exotique, 97, 47-52.

[15] Poda, J.N., Wango, S.P., Sorgho, H. and Dianou, D. (2004) Evolution récente des schistosomoses dans le complexe hydroagricole du Sourou au Burkina Faso. Bulletin de la Société de Pathologie Exotique, 97, 15-18.

[16] Dianou, D., Poda, J.N., Savadogo, L.G., Sorgho, H., Wango, S.P. and Sondo, B. (2004) Parasitoses intestinales dans la zone du complexe hydroagricole du sourou au Burkina Faso. Vertigo-La Revue en Sciences de l'Environnement, 5, 1-8.

[17] Holmboe-Ottesen, G., Wandel, M. and Oshaug, A. (1989) Nutritional Evaluation on an Agricultural Development Project in Southern Sri Lanka. Food and Nutrition Bulletin, 11, 47-56.

[18] Von, B.J. (1988) Effects of Technological Change in Agriculture in Food Consumption and Nutrition: Rice in West African Setting. World Development, 16, 1083-1098. http://dx.doi.org/10.1016/0305-750X(88)90111-8

[19] Bénefice, E. and Simondon, K. (1993) Agricultural Development and Nutrition among Rural Populations: A Case Study of the Middle Valley in Senegal. Ecology of Food and Nutrition, 31, 45-66. http://dx.doi.org/10.1080/03670244.1993.9991349

[20] Niemeijer, R., Guens, M., Kliest, T., Ogonda, V. and Hoorweg, J. (1988) Nutrition in Agricultural Development: The Case of Irrigate Rice Cultivation in West Kenya. Ecology of Food and Nutrition, 22, 65-81. http://dx.doi.org/10.1080/03670244.1988.9991055 